\title{
Proboscis lateralis
}

\author{
Salil Agarwal · Sharat Latta
}

\begin{abstract}
Proboscis lateralis is a rare craniofacial malformation for which no embryological basis has been established. The condition presents with a tubular, nose like structure arising from the medial canthal area or orbit roof. We describe here such a case that was surgically treated.
\end{abstract}

Keywords Proboscis lateralis - Tubular nose · Congenital abnormality

S. Agarwal · S. Latta

Department of ENT, Head and Neck Surgery,

St. Stephens Hospital, Tis Hazari,

Delhi - 110 054, India

\section{S. Agarwal $(\square)$}

E-mail: salilbhavna@hotmail.com

\section{Introduction}

Proboscis lateralis is a rare craniofacial malformation for which no embryological basis has been established. This condition describes a rudimentary nasal structure or appendage that originates from the medial portion of the orbit roof. Besides heminasal aplasia or hypoplasia various other congenital anomalies may coexist.

\section{Case report}

A 16-year-old boy from a missionary orphanage presented with a $4 \times 2 \mathrm{~cm}$ trunk-like appendage arising from his left medial canthus. There was complete absence of left nostril and unilateral cleft lip. In addition, there was coloboma of lower eyelid (Fig. 1).

The boy had no history of difficulty in breathing and any discharge from the appendage. The boy had no other craniofacial or congenital abnormality. A diagnosis of proboscis lateralis was made and the condition explained

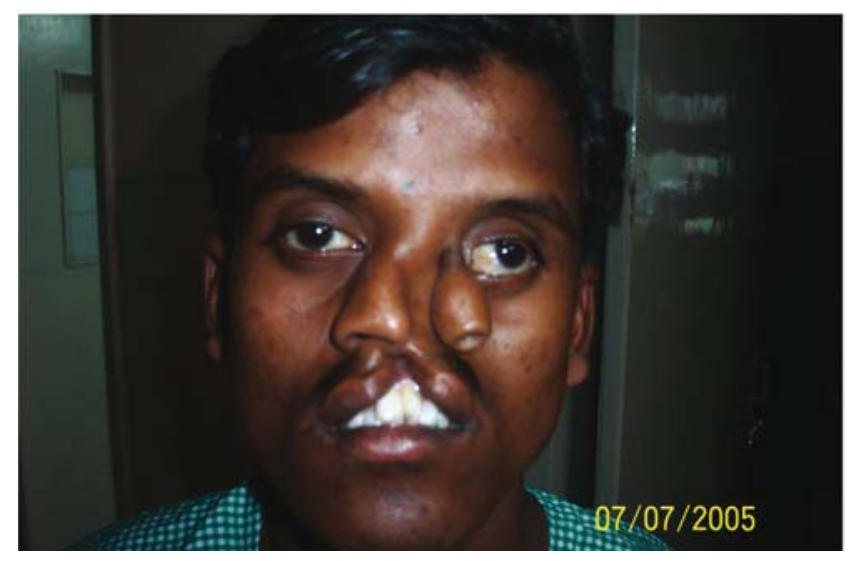

Fig. 1 Rudimentary nasal appendage on left side 


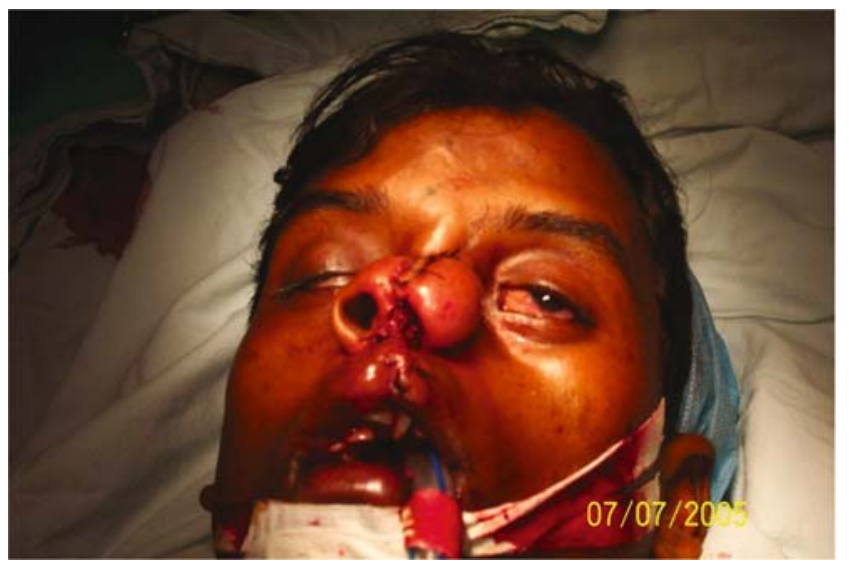

Fig. 2 Reconstruction of rudimentary nasal appendage

to the boy and his guardians. The boy wanted that the appendage be excised. A preoperative counseling was done and the guardians explained that we would be able to reconstruct his nose and repair the cleft lip. The boy was submitted for reconstruction. The proboscis was split and attached to the side of the normal opposite heminose, in addition to repair of the cleft lip (Fig. 2). The boy came once for stitch removal but unfortunately we later lost him to follow up.

\section{Discussion}

Proboscis lateralis is a rare facial anomaly $(1: 100,000$ birth) resulting in incomplete formation of nose, the eye and adnexa [1]. The condition presents with a tubular, nose like structure arising from the medial canthal area or orbit roof. Forster first mentioned this anomaly in 1861 in his monograph Congenital malformation of the human body [2]. Selenkoff in 1884 later described in detail the autopsy findings of a farmer with proboscis [3]. Boo-Chai noted a 2:1 male female preponderance and after a review of literature classified proboscis lateralis into four groups [3]:
1. Proboscis with normal nose

2. Proboscis with nasal defect only

3. Proboscis with nasal defect plus defect of eye and adnexa

4. Proboscis with nasal defect plus abnormality of eye and its adnexa plus cleft lip or palate or both.

Developmental basis of proboscis lateralis is still not clear but it is hypothesized that the embryological defect that results appears to involve the nasal placode which is a primary organizer of the nasal area of the midface [2]. The developmental failure or absence of medial and lateral nasal processes results in fusion of the maxillary process with the contralateral frontal process [4].

Generally, there is heminasal hypoplasia or aplasia on the side of the proboscis although; in rare cases the nose is normal. Cleft lip and/or palate may also be present. It is noteworthy that most patient with proboscis lateralis do not have serious Central nervous system abnormalities.

Management should start early in childhood to avoid psychosocial consequence related to this difficulty [5]. The structure and texture of the proboscis make it an ideal substrate for nasal reconstruction, and for this reason, the proboscis should not be excised if future nasal reconstruction is anticipated.

\section{References}

1. Verma A, Jain N (2005) Proboscis lateralis. Indian Paediatrics 42(6):607

2. Guerrero JM, Cogen MS, Kelly DR, Wiatrak BJ (2001) Proboscis lateralis. Arch Ophthalmol 119(7):1071-1074

3. Boo-Chai K (1985) The Proboscis lateralis - a 14 year follow-up. Plast Reconstr Surg 569

4. Tessier P (1976) Anatomical classification of facial, craniofacial and laterofacial clefts. J Maxillofacial Sur 4:69

5. Vyas UH, Raibagkar SC, Vora HJ, Bhavsar D (2003) Proboscis lateralis - A 17 years follow-up, a case report. Indian J Plast Surg 36:39-42 